\title{
UTILIZAÇÃO DE TUBOS DE PAPELÃO PARA A CONSTRUÇÃO DE UMA ESTRUTURA DE PERGOLADO
}

\author{
USE OF CARDBOARD TUBES FOR THE CONSTRUCTION OF A PERGOLA STRUCTURE
}

\author{
NATHALIA SCHIMIDT DIAS | UNICAMP \\ GERUSA DE CÁSSIA SALADO, Dra.| UNICAMP
}

\begin{abstract}
RESUMO
As estruturas de pergolados são leves e vazadas, formadas pelos apoios, pilares e vigas, podendo ser ou não cobertas. Essas estruturas, geralmente, são construídas com materiais convencionais como, por exemplo, madeira, concreto ou aço, entretanto devido à tipologia da estrutura tem-se com uma das possibilidades a utilização de materiais não-convencionais como, bambu, tubos de papelão etc. Sendo assim, o objetivo deste trabalho é propor a utilização de tubos de papelão para a construção de pergolados em praças públicas, promovendo construções mais sustentáveis e servindo como medida prática para a conscientização ambiental da população. Para isso, foi feito um estudo do local para a implantação de um projeto piloto e todo o desenvolvimento do projeto foi feito com o auxílio das ferramentas computacionais AutoCAD, SketchUp e Lumion. Nos resultados apresenta-se o projeto do pergolado com todos os elementos construtivos, dimensões dos tubos de papelão, além de uma análise de viabilidade econômica, comparando a construção do pergolado com tubos de papelão à construção com a utilização de um material convencional. Com este estudo pode-se concluir que os tubos de papelão têm propriedades satisfatórias de durabilidade e resistência para a construção de pergolados, além de apesentarem viabilidade técnica, ambiental e econômica.
\end{abstract}

PALAVRAS CHAVE: Pergolados; Estruturas; Tubos de Papelão; Materiais não-convencionais.

\begin{abstract}
Pergola structures are light and hollow, formed by supports, pillars and beams, which may or may not be covered. These structures are generally built with conventional materials such as wood, concrete or steel, although due to the typology of the structure there is one of the possibilities of using non-conventional materials such as bamboo, cardboard tubes etc. Therefore, the objective of this work is to propose the use of cardboard tubes for the construction of pergolas in public squares, promoting more sustainable constructions and serving as a practical measure for the environmental awareness of the population. For this, a study of the site was made for the implementation of a pilot project and all the development of the project was done with the help of computational tools AutoCAD, SketchUp and Lumion. The results shows the design of the pergola with all the constructive elements, dimensions of the cardboard tubes, as well as an economic feasibility analysis, in comparison with the construction of the pergola with cardboard tubes and the construction with a conventional material. As this study can be concluded, cardboard tubes have satisfactory properties of durability and resistance for the construction of pergolas, in addition to presenting technical, environmental and economic feasibility.
\end{abstract}

KEY WORDS: Pergola; Structures; Cardboard Tubes; Non-conventional Materials 


\section{INTRODUÇÃO}

As estruturas de pergolados são leves e vazadas e bastante utilizadas na construção civil devido a sua ampla versatilidade arquitetônica e aplicabilidade em áreas diversificadas como parques, praças, comércios e residências (hall de entrada, garagem, jardim, área de lazer etc). Normalmente esse tipo de estrutura semicoberta e semisombreada é utilizada para descanso ou lazer, proporcionando um pouco de sombra sem prejudicar a ventilação e a iluminação natural (PETSCHEK; GASS, 2011).

Estruturalmente os pergolados são formados pelos apoios, pilares, vigas primárias e secundárias, podendo ser ou não cobertos. Quando se opta em realizar a cobertura da estrutura tem-se algumas opções como panos de vidro, policarbonato ou vegetação. Além da diversidade de modelos e das possibilidades de coberturas, para a concepção dos pergolados normalmente utilizam-se materiais convencionais como madeira, metal (alumínio ou aço) e concreto (PETSCHEK; GASS, 2011), contudo também é possível executá-los com materiais não-convencionais como por exemplo o bambu.

Na figura 1 exemplifica-se o Pergolado Bondinho do Pão de Açúcar feito convencionalmente com madeira laminada colada de pinus tratado.

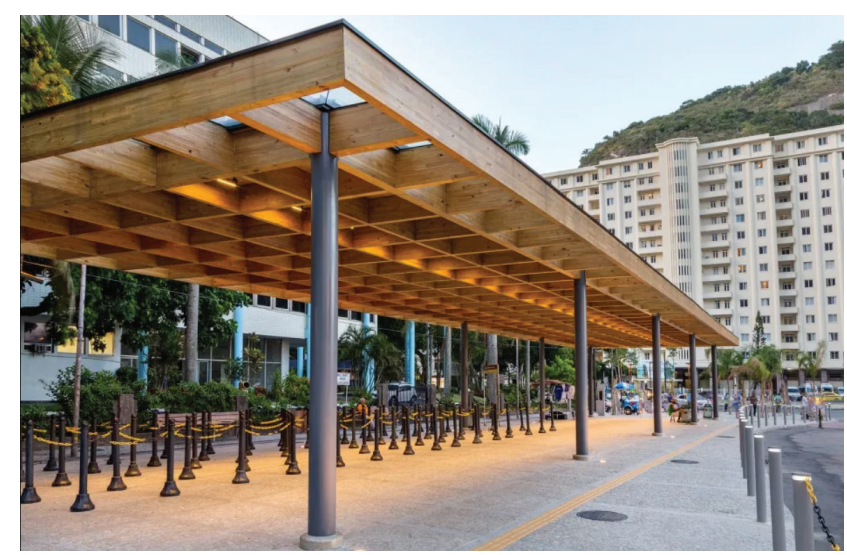

Figura 01 - Pergolado Bondinho do Pão de Açúcar Fonte: Carpinteria, 2021

Na figura 2 mostra-se a construção de um pergolado feito com um material não-convencional. Neste caso toda a estrutura foi feita utilizando bambu.

Além do bambu, outra possibilidade de material não-convencional para a construção de pergolados consiste na utilização de tubos de papelão. De acordo com Dias e Salado (2020), após a análise das obras de Shigeru Ban, constatou-se que os tubos de papelão podem ser empregados na construção civil em diversos sistemas construtivos como: vigas e pilares, painéis portantes, painéis de vedação vertical, tesouras e treliças planas, estruturas em arco, coberturas portantes etc. Assim, pode-se utilizar os tubos de papelão para a concepção de pergolados, já que estas estruturas são basicamente formadas por pilares e vigas.

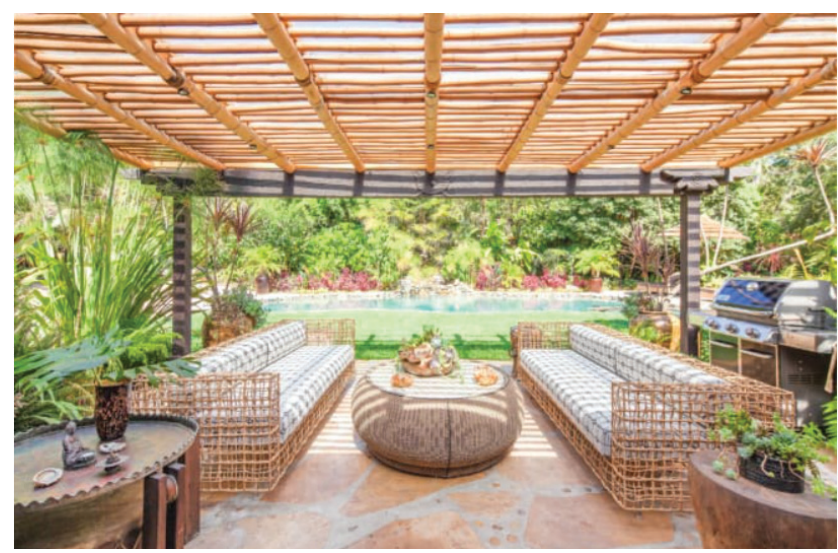

Figura 02 - Pergolado construído com bambu Fonte: Doce0bra, 2021.

Os tubos de papelão são atrativos para a utilização na construção civil, uma vez que são elementos baratos, não necessitam de grande tecnologia para a produção e podem ser facilmente reaproveitados ou reciclados (MCQUAID, 2003). Além de serem uma opção sustentável e ambientalmente ecológica, os tubos de papelão também são viáveis tecnicamente pois apresentam resistência e durabilidade satisfatórias para compor obras de construção civil (DIAS; CAMARGO e SALADO, 2019).

Considerando-se o exposto acima, este trabalho tem como objetivo propor a utilização de tubos de papelão para a construção de uma estrutura de pergolado em uma praça pública, proporcionando uma construção permanente mais sustentável e com menos impactos ao meio ambiente. No mais, esta construção visa servir como medida prática para a conscientização ambiental da população, bem como a quebra de paradigmas em relação ao uso de materiais não-convencionais em construções e em especial ao material escolhido.

Com o desenvolvimento deste trabalho pretende-se propor um projeto de extensão, o qual será apresentado à Prefeitura Municipal de Limeira, com o intuito de realizar a implantação destes pergolados em algumas praças públicas da cidade.

A importância desse estudo relaciona-se diretamente com a utilização de materiais não- convencionais, demonstrando que estas construções atendem aos requisitos de resistência e durabilidade, aliados a sustentabilidade ambiental e viabilidade econômica, uma vez que 
se utiliza um material reciclado, salubre e de menor custo. No mais percebe-se que esse estudo permite que a população tenha contato com um material distinto aos convencionais e conheça uma possível aplicação em obras urbanas e de passagem.

\section{METODOLOGIA}

Neste trabalho, inicialmente, foram estudadas algumas praças públicas para avaliar a possibilidade de implantação de um projeto piloto de pergolado. Para isso utilizou-se a ferramenta do Google Maps, a qual permite a visualização em planta e do entorno das possíveis praças. Na triagem inicial levou-se em consideração fatores como: a extensão do local, a localização, o entorno (comercial ou residencial), fluxo de pessoas e os equipamentos urbanos já instalados.

Após a seleção de algumas praças pelo Google Maps, foi feita a visita in loco para identificar a real situação dos espaços, bem como visualizar a topografia do terreno e realizar as medições necessárias para implantar o pergolado proposto.

Ao fim das visitas aos locais selecionados, foi escoIhida para a realização do projeto a praça Dr. Nelson de Barros Camargo que se localiza próxima ao campus da Universidade Estadual de Campinas (Faculdade de Tecnologia - FT), na cidade de Limeira, São Paulo. Posteriormente a realização do estudo do local, estudo do entorno e do fluxo de pessoas, identificou-se que esta praça poderia ser uma boa escolha por ser frequentada por moradores do entorno e também por estudantes, já que devido à sua proximidade com o campus da universidade, o local torna-se parte do trajeto para muitos universitários.

Na figura 3 demonstra-se parcialmente o mapa da cidade de Limeira e a localização da praça escolhida.

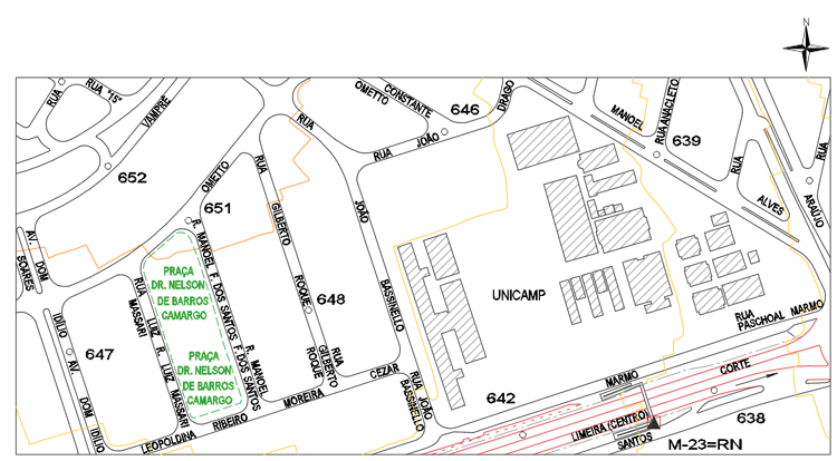

Figura 03 - Mapa com a Praça Dr. Nelson de Barros Camargo

Fonte: Prefeitura Municipal de Limeira, 2019.

Além da localização da praça, para a escolha do local também se levou em consideração a topografia do terreno. Optou-se pela escolha de um local bastante plano, a fim de evitar gastos com terraplanagem, corte e aterro. Em adição, o local escolhido já possui algumas áreas de lazer como academia, campos de futebol e quadra, tornando assim a proposta de intervenção com uma estrutura de pergolado bastante interessante e coerente.

Nas figuras 4 a 7 demonstram-se as áreas verdes e de lazer da praça Dr. Nelson de Barros Camargo, Limeira, SP.

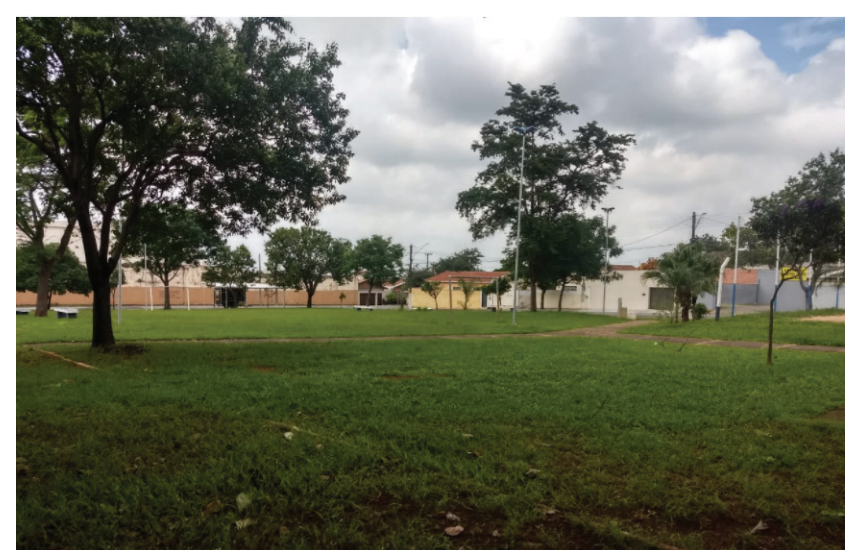

Figura 04 - Vista para o campo de futebol Fonte: As autoras.

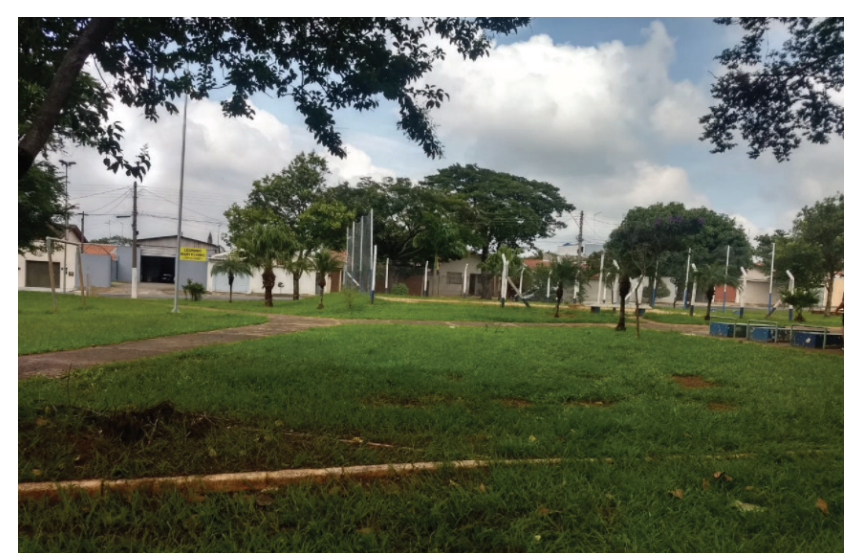

Figura 05 - Vista para o campo de futebol de areia Fonte: As autoras.

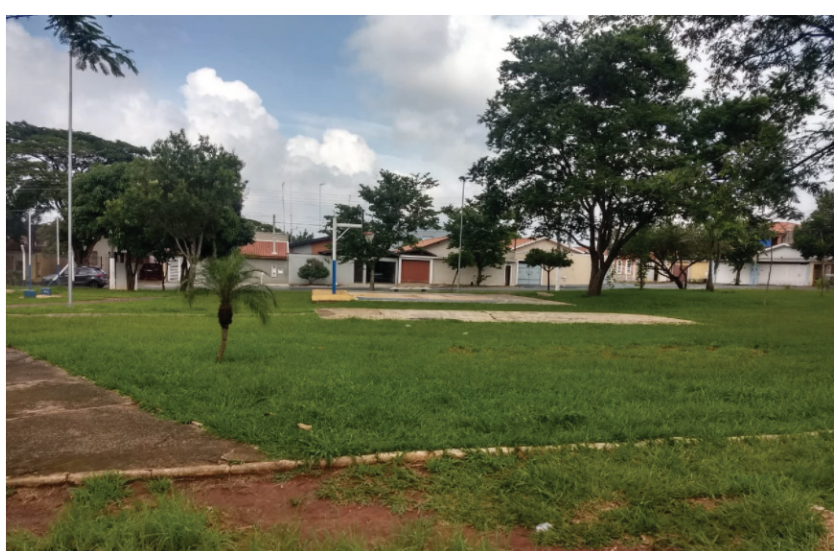

Figura 06 - Vista para a quadra de basquete Fonte: As autoras. 


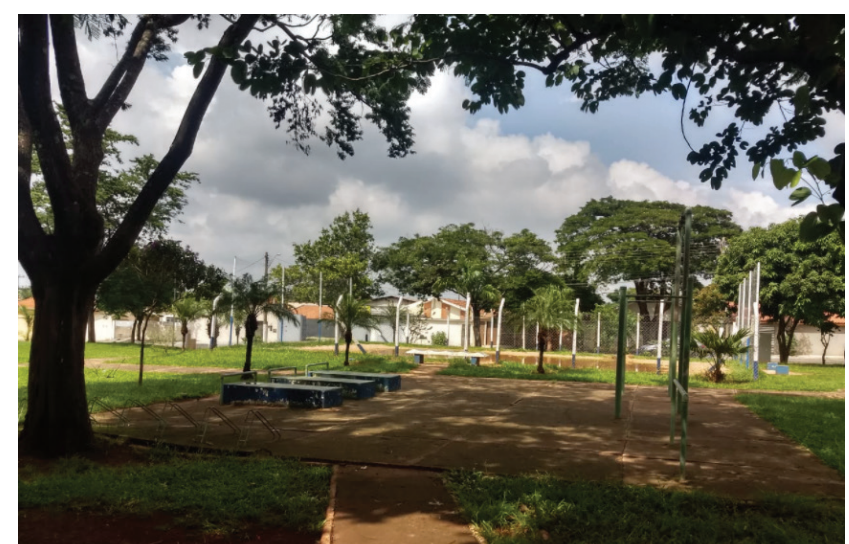

Figura 07 - Academia em frente ao campo de futebol de areia Fonte: As autoras.

Após o estudo do local, fez-se o estudo para entender o melhor local para a implantação do pergolado. Assim, resolveu-se propor o projeto piloto do pergolado de forma que este fosse posicionado no melhor local, sem interferir radicalmente na paisagem e disposto para o melhor aproveitamento possível da população local e visitante. Para o desenvolvimento do projeto foi necessária a medição de algumas áreas no local e posteriormente foram utilizados programas computacionais como AutoCAD, SketchUp e Lumion para elaborar o projeto e executar a
Nas figuras 8 e 9 demonstra-se o local de implantação bem como a planta baixa para a colocação do pergolado de tubos de papelão.

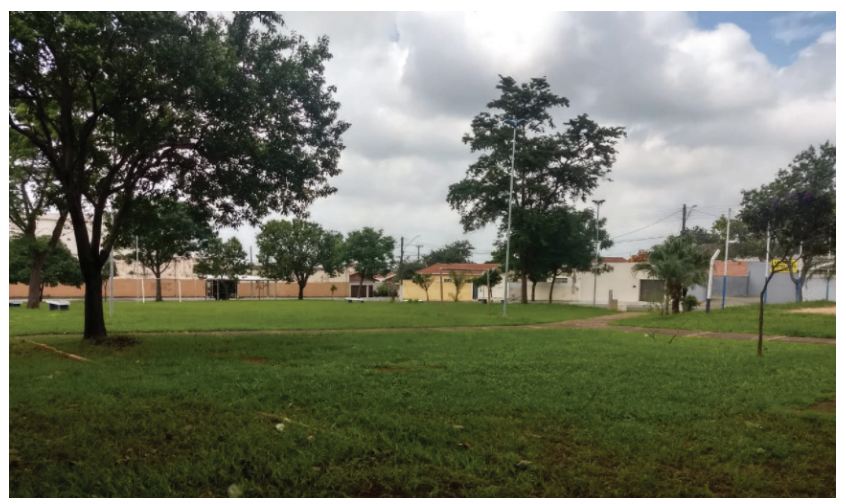

Figura 08 - Espaço utilizado para a implantação do pergolado Fonte: As autoras.

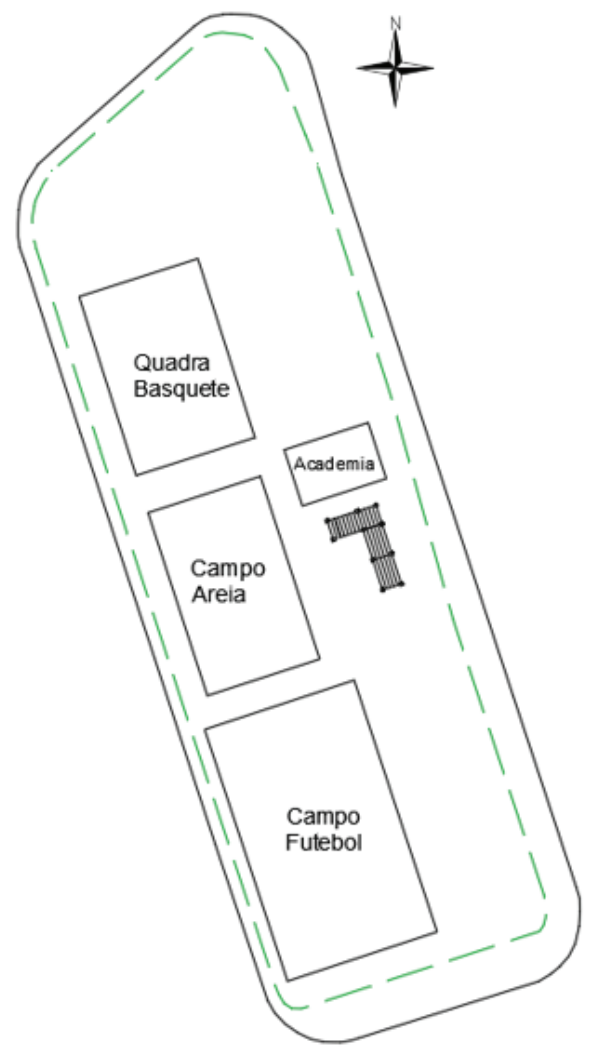

Figura 09 - Planta baixa do local para a implantação do pergolado Fonte: As autoras.

\subsection{Projeto do pergolado com tubos de papelão}

Para o desenvolvimento do projeto foram considerados alguns fatores como:

- Escolha do local: escolheu-se um lugar bem ao centro da praça, com poucas árvores e bastante plano para que não fossem necessários gastos com corte e aterro; 
- Forma do pergolado: optou-se por projetar a estrutura em formato de $L$ para que esta proporcionasse o meIhor aproveitamento do espaço disponível. Também foi considerada que a implantação deveria ocorrer em um local onde não houvesse a necessidade de modificar as passarelas de concreto já existentes;

- Elementos estruturais: para o dimensionamento do projeto piloto da estrutura foram considerados fatores como: diâmetros dos tubos de papelão e espessura da parede para os pilares, vigas primárias (colocadas como cintas de amarração) e vigas secundarias (grades do pergolado), além do espaçamento máximo entre os pilares, evitando grandes vãos. Em adição, pensou-se em elementos de fundação e de vedação para os topos dos pilares, além da aplicação de resinas para proteção dos tubos de papelão, sendo esta aplicação fundamental para garantir durabilidade à estrutura;

- Cobertura do pergolado: os pergolados podem ser ou não cobertos, no caso deste projeto piloto optou-se pela cobertura vegetal como uma opção mais sustentável e também para gerar sombra ao local, visto que a estrutura foi inserida em um local com poucas árvores ao redor e sem sombreamento.

\subsection{Apresentação do projeto do pergolado}

Primeiramente faz-se necessário apresentar o projeto piloto da estrutura do pergolado composto pelos apoios, pilares, vigas primárias e secundárias.

Na figura 10 demonstra-se a planta baixa com todas as dimensões do pergolado proposto para a praça Dr. Nelson de Barros Camargo.

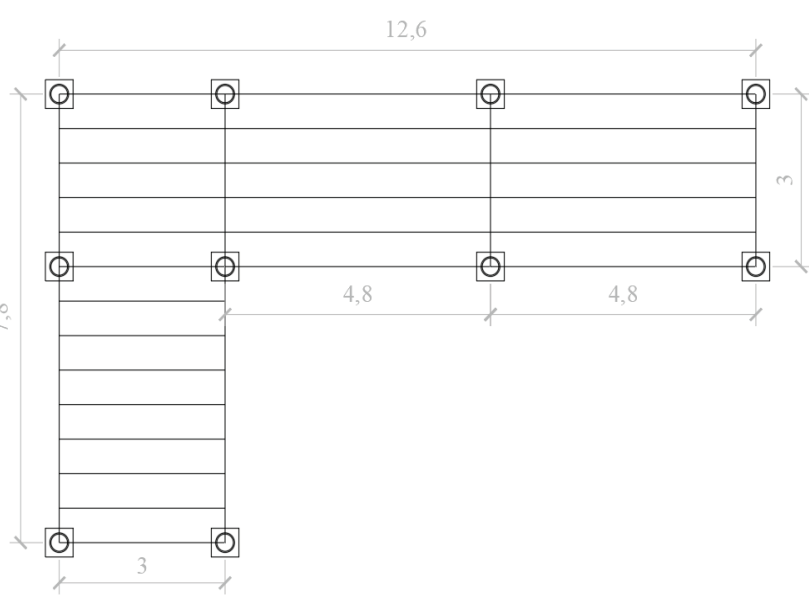

Figura 10 - Planta baixa do pergolado com dimensões em metros Fonte: As autoras.

Para proporcionar uma melhor visualização do pergolado e seus elementos estruturais, na figura 11 apresenta-se o projeto tridimensional, o qual foi desenvolvido com a utilização do software Autodesk AutoCAD.

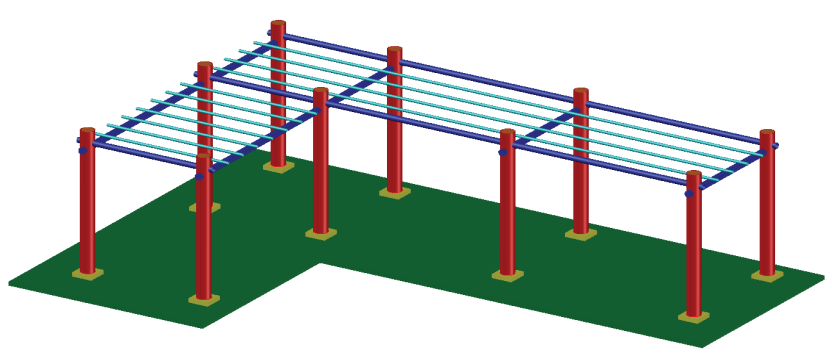

Figura 11 - Projeto tridimensional do pergolado com tubos de papelão Fonte: As autoras.

Com todo o dimensionamento da estrutura e as considerações do projeto piloto apresentados, nas figuras 12 e 13 demonstra-se a vista superior e frontal do projeto renderizado no software Lumion com a cobertura de vegetação e com os bancos de madeira.

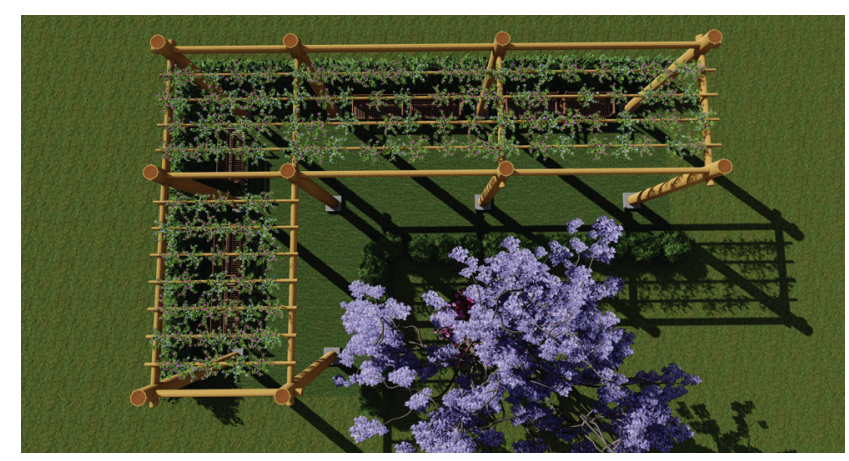

Figura 12 - Vista superior do pergolado renderizado Fonte: As autoras.

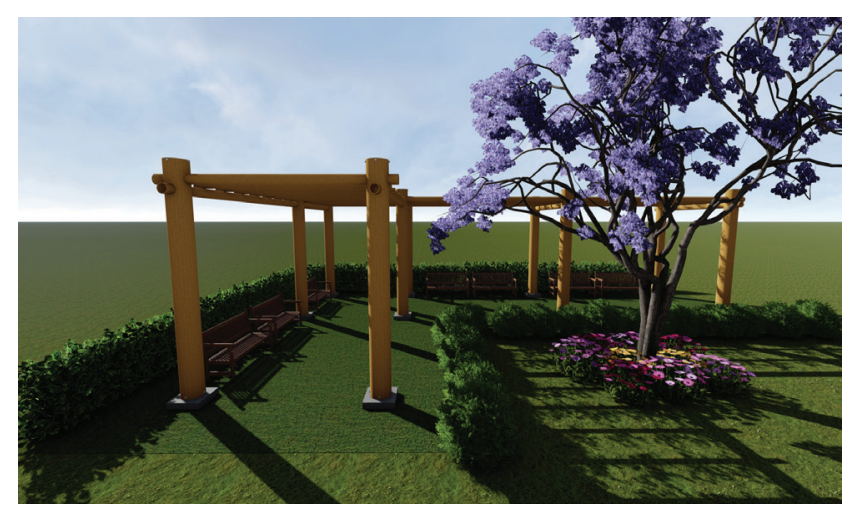

Figura 13 - Vista frontal do pergolado renderizado Fonte: As autoras.

De forma a quantificar e detalhar os tubos de papelão utilizados para a elaboração do projeto, na tabela 1 apesentam-se todos os elementos estruturais, quantidades, comprimentos, diâmetros (interno e externo) e espessuras. Além do mais, ressalta-se que em todos os elementos foram consideradas as dimensões comerciais encontradas, e quanto ao comprimento levou-se em consideração também a perfuração e o transpasse dos tubos de papelão. 


\begin{tabular}{|c|c|c|c|c|c|}
\hline \multicolumn{6}{|c|}{ Pergolado com Tubos de Papelão } \\
\hline $\begin{array}{l}\text { Elementos estruturais } \\
\text { - Tubos de Papelão }\end{array}$ & Quantidade & Comprimento (m) & $\begin{array}{l}\text { Diâmetro } \\
\text { interno }(\mathrm{cm})\end{array}$ & $\begin{array}{l}\text { Diâmetro } \\
\text { externo }(\mathrm{cm})\end{array}$ & Espessura (mm) \\
\hline Pilares (vermelho) & 10 & 3,50 & 30,00 & 34,00 & 20,00 \\
\hline \multirow{5}{*}{$\begin{array}{l}\text { Vigas primárias } \\
\text { (azul escuro) }\end{array}$} & 3 & 3,50 & 13,00 & 15,00 & 10,00 \\
\hline & 4 & 5,00 & 13,00 & 15,00 & 10,00 \\
\hline & 2 & 3,10 & 13,00 & 15,00 & 10,00 \\
\hline & 2 & 3,30 & 13,00 & 15,00 & 10,00 \\
\hline & 2 & 4,80 & 13,00 & 15,00 & 10,00 \\
\hline \multirow{4}{*}{$\begin{array}{l}\text { Vigas secundá- } \\
\text { rias (azul claro) }\end{array}$} & 7 & 3,50 & 5,00 & 7,00 & 10,00 \\
\hline & 4 & 3,30 & 5,00 & 7,00 & 10,00 \\
\hline & 4 & 5,00 & 5,00 & 7,00 & 10,00 \\
\hline & 4 & 4,80 & 5,00 & 7,00 & 10,00 \\
\hline
\end{tabular}

Tabela 01: Dimensões dos tubos de papelão utilizados no pergolado Fonte: As autoras.

Para abranger mais ângulos, nas figuras 14 e 15 pode-se visualizar a parte posterior do pergolado e a vista interna.

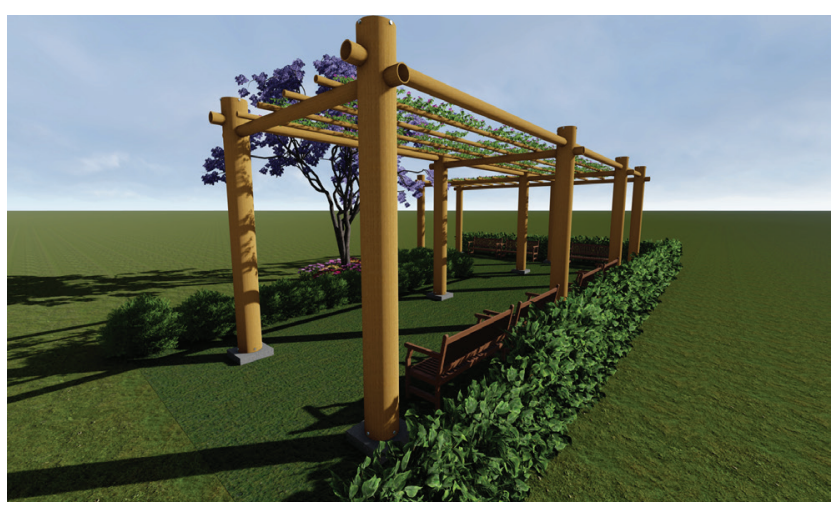

Figura 14 - Vista posterior do pergolado renderizado Fonte: As autoras.

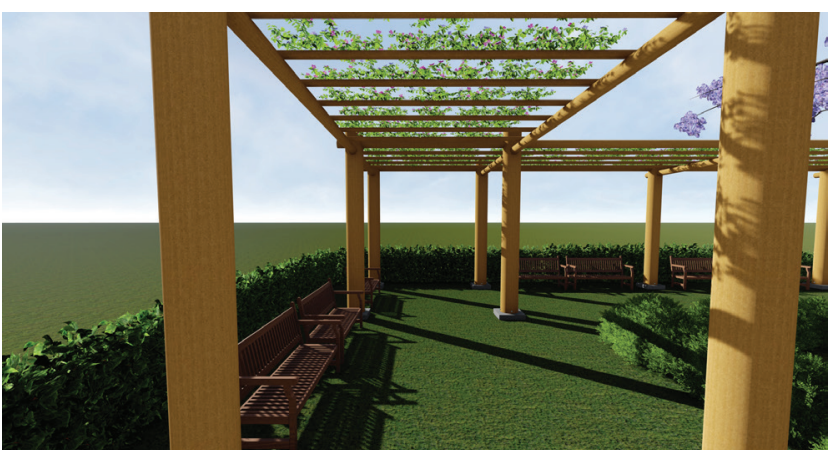

Figura 15 - Vista interna do pergolado renderizado Fonte: As autoras.

O pergolado proposto foi desenvolvido inteiramente com perfuração e transpasse dos tubos de papelão, dessa forma não houve a necessidade de projetar peças de ligações para realizar a conexão das vigas aos pilares. A solução de perfurar e transpassar os tubos gera economia para a obra uma vez que não é necessário gastar com os elementos de ligação; além disso essa alternativa para conectar os tubos de papelão já foi muito utilizada em outras construções com este material e principalmente quando tratam-se de estruturas mais leves.

Para os tubos de papelão menores (vigas secundárias) que não foram transpassados, optou-se pela sobreposição à estrutura principal (vigas primárias). Neste caso pode-se utilizar duas soluções para a fixação, sendo a primeira feita por parafusos e a segunda consiste na amarração com cordas. Vale ressaltar que a solução de amarrar os tubos de papelão menores à estrutura principal também já foi utilizada em obras com tubos de papelão.

Na figura 16 demonstra-se o detalhe da perfuração e transpasse dos tubos de papelão no pergolado. Ainda, no topo de cada pilar foi colocada uma bolacha de madeira parafusada com $5 \mathrm{~cm}$ de altura, evitando-se dessa forma o acúmulo de poeira ou retenção de águas pluviais no interior dos pilares.

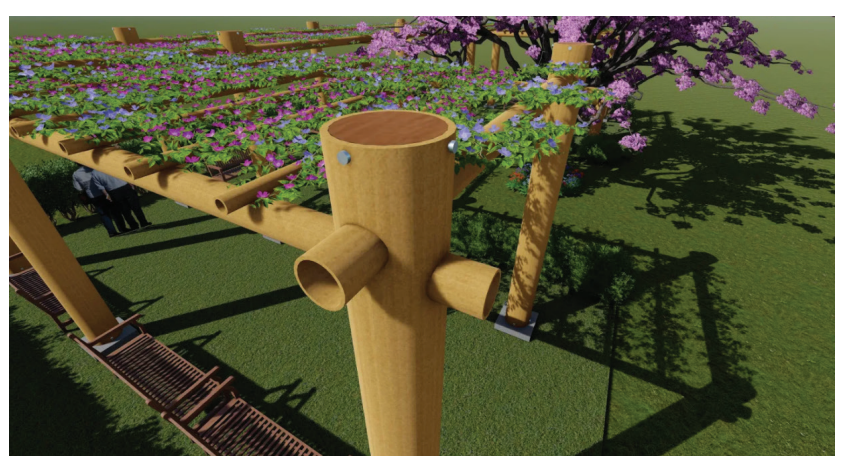

Figura 16 - Detalhe da perfuração e transpasse dos tubos de papelão e da bolacha de madeira parafusada no topo.

Fonte: As autoras. 
Na parte inferior dos tubos de papelão foram projetadas bases em concreto para o encaixe dos tubos e a fixação através de parafusos. Além de servir como fundação superficial, estas bases foram projetadas para elevar os tubos de papelão de forma a evitar que haja contato direto com o solo e impedindo que os tubos de papelão absorvam umidade.

Na figura 17 pode-se visualizar uma das bases de concreto com o tubo de papelão já parafusado.

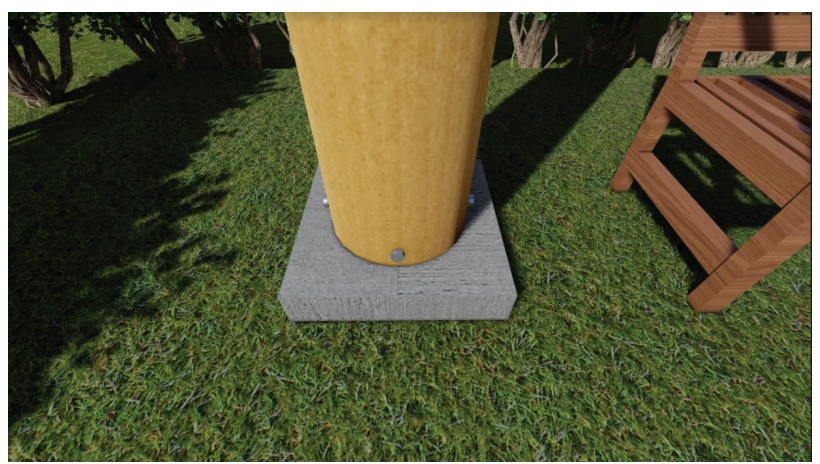

Figura 17 - Detalhe da base de concreto com tubo de papelão fixado Fonte: As autoras.

Na figura 18 demonstra-se o modelo da base de concreto. Estas bases foram projetadas com duas barras de aço presas na diagonal, as quais proporcionam a ancoragem ao solo.

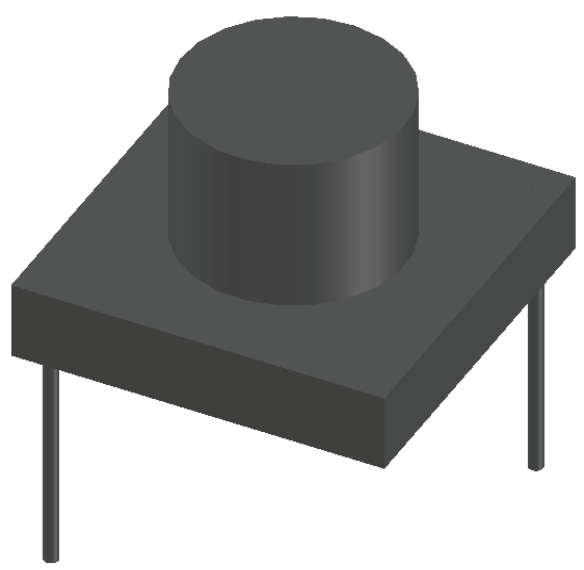

Figura 18 - Modelo da base de concreto com as barras de aço para a ancoragem ao solo. Fonte: As autoras.

Além das bases de concreto, adotou-se também a utilização de anéis de borracha colocados entre os tubos de papelão e as bases de concreto. Para Salado (2011), os anéis de borracha evitam o contato direto dos tubos de papelão com a água e impedem a absorção de umidade pelos elementos de papelão.

Além dos elementos colocados no topo e na base dos tubos de papelão, ressalta-se que todos os tubos de papelão devem ser impermeabilizados com resina evitando que haja absorção de umidade e também realizando a proteção contra as incidências solares, garantindo assim durabilidade à estrutura. Frisa-se que a durabilidade estimada para o material, segundo Shigeru Ban, é de pelo menos 10 anos (ARCHITECTURE AND URBANISM, 1997 apud SALADO, 2011).

Para Dias, Camargo e Salado (2019), uma construção é considerada sustentável se apresentar viabilidade técnica, ambiental e econômica, uma vez que esses três fatores devem atuar em conjunto na construção.

Para Salado (2003), com relação a viabilidade técnica, os tubos de papelão apresentam resistência satisfatórias para o seu emprego na construção civil. No mais, após a realização de ensaios por Dias (2017), Salado (2006) e Eeckout et al., (2008), pode-se verificar que os tubos de papelão constituem uma solução viável tecnicamente, apresentando bons valores de resistência à compressão e à tração, principalmente considerando-se as características do material como o baixo peso específico e as espessuras de parede.

Com relação a sustentabilidade ambiental das construções, esta relaciona-se diretamente com seis fatores como: diminuição do consumo dos recursos; utilização de recursos renováveis e recicláveis; reutilização de recursos; preservação do ambiente natural; preservação das condições de salubridade do ambiente e capacidade de manter a alta qualidade para o desenvolvimento do ambiente construído (PINHEIRO, 2003).

Dentre os materiais que podem ser reaproveitados, tem-se o papel, o qual é produzido em grandes quantidades, podendo ser reciclado e utilizado como material de construção civil (GRIGOLETTO, 2011). Já no contexto brasileiro, em 2019, o Brasil atingiu uma taxa de $66,9 \%$ de reciclagem do material e atualmente $100 \%$ do papel produzido tem origem em árvores cultivadas para este fim, tornando o papel um recurso sustentável, de origem natural e reciclável (IBÁ, 2020).

Considerando-se a viabilidade econômica como um dos pilares analisados para uma construção sustentável e após a elaboração do projeto com tubos de papelão para a realização do pergolado, realizou-se a estimativa dos custos para a execução da obra. Para realizar um comparativo sobre a viabilidade econômica, além do orçamento dos tubos de papelão, apresenta-se também uma proposta de construção do mesmo pergolado utilizando um material convencional, no caso optou-se pelo eucalipto tratado, o qual é bastante empregado para a realização deste tipo de construção.

Na tabela 2 apresenta-se o orçamento realizado para a construção com tubos de papelão, considerando todos os transpasses e dimensões produzidos pela indústria, bem como as bases em concreto e o material para recortar as bolachas de madeira (tábua de madeira). 


\begin{tabular}{|c|c|c|c|}
\hline Descrição & Quant. & \begin{tabular}{|l|} 
Custo \\
unitário \\
\end{tabular} & Custo total \\
\hline $\begin{array}{l}\text { Tubos de papelão com } \\
\text { diâmetro interno de } 30 \\
\mathrm{~cm} \text {, espessura de } 20 \mathrm{~mm} \text { e } \\
3,50 \mathrm{~m} \text { de comprimento }\end{array}$ & 10 & $R \$ 520,80$ & $R \$ 5.208,00$ \\
\hline $\begin{array}{l}\text { Tubos de papelão com } \\
\text { diâmetro interno de } 13 \\
\text { cm, espessura de } 10 \mathrm{~mm} \text { e } \\
3,50 \mathrm{~m} \text { de comprimento }\end{array}$ & 3 & $R \$ 113,52$ & $R \$ 340,56$ \\
\hline $\begin{array}{l}\text { Tubos de papelão com } \\
\text { diâmetro interno de } 13 \\
\text { cm, espessura de } 10 \mathrm{~mm} \text { e } \\
5,00 \mathrm{~m} \text { de comprimento }\end{array}$ & 4 & $R \$ 162,17$ & $R \$ 648,68$ \\
\hline $\begin{array}{l}\text { Tubos de papelão com } \\
\text { diâmetro interno de } 13 \\
\text { cm, espessura de } 10 \mathrm{~mm} \text { e } \\
3,10 \mathrm{~m} \text { de comprimento }\end{array}$ & 2 & $R \$ 100,54$ & $R \$ 201,08$ \\
\hline $\begin{array}{l}\text { Tubos de papelão com } \\
\text { diâmetro interno de } 13 \\
\mathrm{~cm} \text {, espessura de } 10 \mathrm{~mm} \text { e } \\
3,30 \text { m de comprimento }\end{array}$ & 2 & $R \$ 107,03$ & $R \$ 214,06$ \\
\hline $\begin{array}{l}\text { Tubos de papelão com } \\
\text { diâmetro interno de } 13 \\
\text { cm, espessura de } 10 \mathrm{~mm} \text { e } \\
4,80 \mathrm{~m} \text { de comprimento }\end{array}$ & 2 & $R \$ 155,68$ & $R \$ 311,36$ \\
\hline $\begin{array}{l}\text { Tubos de papelão com } \\
\text { diâmetro interno de } 05 \\
\text { cm, espessura de } 10 \mathrm{~mm} \text { e } \\
3,50 \mathrm{~m} \text { de comprimento }\end{array}$ & 7 & $R \$ 48,83$ & $R \$ 341,81$ \\
\hline $\begin{array}{l}\text { Tubos de papelão com } \\
\text { diâmetro interno de } 05 \\
\text { cm, espessura de } 10 \mathrm{~mm} \text { e } \\
3,30 \mathrm{~m} \text { de comprimento } \\
\end{array}$ & 4 & $R \$ 46,04$ & $\mathrm{R} \$ 184,16$ \\
\hline $\begin{array}{l}\text { Tubos de papelão com } \\
\text { diâmetro interno de } 05 \\
\text { cm, espessura de } 10 \mathrm{~mm} \text { e } \\
5,00 \mathrm{~m} \text { de comprimento }\end{array}$ & 4 & $\mathrm{R} \$ 69,75$ & $R \$ 279,00$ \\
\hline $\begin{array}{l}\text { Tubos de papelão com } \\
\text { diâmetro interno de } 05 \\
\mathrm{~cm} \text {, espessura de } 10 \mathrm{~mm} \text { e } \\
\text { 4,80 m de comprimento }\end{array}$ & 4 & $\mathrm{R} \$ 66,96$ & $R \$ 267,84$ \\
\hline $\begin{array}{l}\text { Bases em concreto } 20 \\
\text { MPa com } 50 \times 50 \times 10 \mathrm{~cm} \text { e } \\
\text { cilindros com diâmetro de } \\
30 \mathrm{~cm} \text { e altura de } 20 \mathrm{~cm}\end{array}$ & 10 & $\mathrm{R} \$ 11,20$ & $\mathrm{R} \$ 112,00$ \\
\hline $\begin{array}{l}\text { Tábua de madeira em pinus } \\
\text { com } 29,5 \times 4,5 \times 400 \mathrm{~cm}\end{array}$ & 1 & $R \$ 229,90$ & $R \$ 229,90$ \\
\hline \multicolumn{3}{|c|}{\begin{tabular}{|l|l} 
TOTAL \\
\end{tabular}} & $\mathrm{R} \$ \mathbf{8 . 3 3 8 , 4 5}$ \\
\hline
\end{tabular}

Tabela 02: Custos para a construção do pergolado com tubos de papelão Fonte: As autoras.

Além do orçamento realizado para a construção com tubos de papelão, foi feita a estimativa de custos para a construção do mesmo pergolado, contudo com a utilização de eucalipto tratado. Todos os valores foram aferidos no site Global Pedras, considerando as dimensões mais aproximadas e ideais para a estimativa de custos.
Em ambos os casos há a necessidade de impermeabilização/tratamento com aplicação de resina, contudo sabendo-se que as quantidades e custo seriam iguais, a resina não foi contabilizada para o orçamento. Dessa forma, ressalta-se que a análise de custos incluiu apenas os materiais utilizados para as duas construções, excluindo-se também os custos relativos à mão-de-obra e ao transporte.

Analisando-se os valores totais apresentados nas tabelas 2 e 3, notou-se que a construção com tubos de papelão apresentou-se um pouco mais barata que a construção com eucalipto. Verificou-se que a estrutura feita com tubos de papelão proporcionou uma economia de aproximadamente $11,91 \%$ em relação a construção feita com eucalipto tratado.

A estimativa de custos para a construção feita com eucalipto tratado, bem como as descrições das toras (com diâmetro e comprimento) e as quantidades, são detalhadas e apresentadas na tabela 3.

\begin{tabular}{|c|c|c|c|}
\hline \multicolumn{4}{|c|}{ Pergolado - Eucalipto Tratado } \\
\hline Descrição & Quant. & $\begin{array}{l}\text { Custo } \\
\text { unitário }\end{array}$ & Custo total \\
\hline $\begin{array}{l}\text { Eucalipto tratado com } \\
\text { diâmetro de } 30 \text { a } 35 \mathrm{~cm} \text { e } \\
7,00 \mathrm{~m} \text { de comprimento }\end{array}$ & 5 & $\mathrm{R} \$ 1.384,00$ & $\mathrm{R} \$ 6.920,00$ \\
\hline $\begin{array}{l}\text { Eucalipto tratado com } \\
\text { diâmetro de } 14 \text { a } 16 \mathrm{~cm} \text { e } \\
3,00 \mathrm{~m} \text { de comprimento }\end{array}$ & 5 & $\mathrm{R} \$ 91,00$ & $R \$ 455,00$ \\
\hline $\begin{array}{l}\text { Eucalipto tratado com } \\
\text { diâmetro de } 14 \text { a } 16 \mathrm{~cm} \text { e } \\
8,0 \text { m de comprimento }\end{array}$ & 2 & $R \$ 333,00$ & $R \$ 666,00$ \\
\hline $\begin{array}{l}\text { Eucalipto tratado com } \\
\text { diâmetro de } 14 \text { a } 16 \mathrm{~cm} \text { e } \\
5,0 \mathrm{~m} \text { de comprimento }\end{array}$ & 4 & $R \$ 152,00$ & $\mathrm{R} \$ 608,00$ \\
\hline $\begin{array}{l}\text { Eucalipto tratado com } \\
\text { diâmetro de } 06 \text { a } 08 \mathrm{~cm} \text { e } \\
3,00 \mathrm{~m} \text { de comprimento }\end{array}$ & 11 & $R \$ 25,50$ & $\mathrm{R} \$ 280,50$ \\
\hline $\begin{array}{l}\text { Eucalipto tratado com } \\
\text { diâmetro de } 06 \text { a } 08 \mathrm{~cm} \\
5,00 \text { m de comprimento }\end{array}$ & 8 & $\mathrm{R} \$ 67,00$ & $\mathrm{R} \$ 536,00$ \\
\hline & & TOTAL & $\mathrm{R} \$ \mathbf{9 . 4 6 5 , 5 0}$ \\
\hline
\end{tabular}

Tabela 03: Estimativa de custo para a construção do pergolado com eucalipto tratado Fonte: As autoras.

\section{CONCLUSÕES}

A utilização dos tubos de papelão para a concepção de uma estrutura como um pergolado torna-se atrativa devido a sustentabilidade ambiental, proporcionando uma construção mais sustentável e com menor impacto ao meio ambiente, pois utiliza-se um material reciclado e que pode ser facilmente reciclado posteriormente. Além disso, a implantação desse tipo de construção em um 
local público serve como medida prática para a conscientização ambiental da população bem como a quebra de paradigmas em relação ao material escolhido.

A proposta de utilização dos tubos de papelão também remete a evolução das técnicas construtivas e a transferência de tecnologias, disseminando o desenvolvimento das ideias estudadas na área acadêmica, uma vez que se demonstra que outros materiais diferentes dos convencionais (madeira, aço e concreto) podem compor obras de engenharia e arquitetura.

A implantação de um projeto piloto do tipo pergolado não interfere radicalmente na mudança da paisagem urbana sendo possível executá-los em diversos locais como praças públicas, desde que sejam feitas as adaptações necessárias para adequar-se ao espaço disponível. Para propor uma obra sustentável, além da escolha do material, faz-se necessária a análise da viabilidade da construção, pois os requisitos de disponibilidade dos recursos e localização são fundamentais para implantação do projeto.

A utilização de tubos de papelão para a construção de uma estrutura de pergolado pode ser considerada técnica e ambientalmente adequada, além de apresentar-se viável economicamente, demonstrando uma redução de $11,91 \%$ nos custos para a implantação de uma construção idêntica feita com eucalipto tratado.

Para manter a segurança e a durabilidade da estrutura depende-se de alguns fatores como a colocação de elementos para a vedação superior (através de bolachas de madeira) e também da elevação dos tubos de papelão em relação ao solo (bases de concreto), evitando-se a deterioração dos pilares causada pela absorção de umidade. Além disso, assim como nos pergolados em madeira, faz-se necessário o tratamento com aplicação de resina evitando a absorção de umidade, diminuindo os danos causados pela incidência dos raios ultravioletas e a proliferação de fungos e insetos.

Frisa-se que os tubos de papelão podem ser utilizados para compor estruturalmente o pergolado da mesma forma que outros materiais como a madeira e o bambu, mantendo características como resistência e durabilidade satisfatórias. Frisa-se que a estabilidade estrutural se relaciona com o conhecimento das propriedades e limitações de cada material e não apenas à sua resistência mecânica, bem como a durabilidade da estrutura depende também do tratamento correto dos elementos, uso e operação e das manutenções periódicas preventivas.

\section{AGRADECIMENTOS}

O presente trabalho foi realizado com apoio da Coordenação de Aperfeiçoamento Pessoal de Nível Superior - Brasil - (CAPES) - Código de Financiamento 001.

\section{REFERÊNCIAS}

CAMARGO, B. S.; SALADO, G. C. Sustentabilidade no uso de tubos de papelão aplicados na construção civil. VII Encontro de Sustentabilidade em projeto. Santa Catarina, 2019.

CARPINTERIA. Pergolado Bondinho. Disponível em: https://carpinteria.com.br/project/pergolado-bondinho/ Acesso em 31/01/2021 às 16:22.

DIAS, N. S.; SALADO, G. C. . Construções com tubos de papelão: um estudo dos sistemas construtivos durante 2007-2017. Palhoça: Encontro de Sustentabilidade em Projeto (ENSUS). Anais do VII Encontro de Sustentabilidade em Projeto, 2020. V. 1. p. 105-116.

DIAS, N. S.; CAMARGO, B. S. ; SALADO, G. C. . Elementos tubulares de papel reciclado utilizados como elemento construtivo: uma possibilidade viável de uso dos resíduos em termos técnicos, econômicos e de sustentabilidade ambiental. Belém: Encontro Nacional sobre Aproveitamento de Resíduos na Construção Civil - ENARC. Anais do VI Encontro Nacional sobre Aproveitamento de Resíduos na Construção Civil, 2019.

DIAS, N. S. Estudo e proposta de sistema estrutural com tubos de papelão. Relatório (Iniciação Científica). Limeira: Universidade Estadual de Campinas: Faculdade de Tecnologia, 2017.

DOCEOBRA. Pergolado de Bambu. Disponível em: https://casaeconstrucao.org/projetos/pergolado-de-bambu/ Acesso em 31/01/2021 às 16:32.

GLOBAL PEDRAS. Eucalipto tratado. Disponível em: $\quad$ https://www.globalpedras.com.br/eucalipto-tratado?fq=gDi\%C3\%A2metro+:5267504 Acesso em 27/06/2021 às 16:15.

GRIGOLETTO, I. C. Reaproveitar e reciclar o papel: proposta de conscientização da preservação ambiental. (Monografia de especialização). Santa Maria, RS: Universidade Federal de Santa Maria, 2011.

IBÁ - Indústria Brasileira de Árvores. Relatório Anual 2020. Disponível em: https://twosides.org.br/wp-content/uploads/sites/15/2020/10/relatorio-iba-2020.pdf Acesso em 01/02/2021 às 14:36

McQUAID, M. Shigeru Ban. Nova York: Phaidon Press, 
2003.

PINHEIRO, M. D. Construção sustentável: mito ou realidade. Lisboa: VII Congresso Nacional de Engenharia do Ambiente, 2003.

PREFEITURA MUNICIPAL DE LIMEIRA. Legislação, mapas e dados. Disponível em: https://www.limeira.sp.gov.br/sitenovo/simple_hotsite.php?id=29\&simple $=118$. Publicado em 03/01/2019. Acesso em 31/01/2021 às 17:03.

PETSCHEK, P.; GASS, S. Constructing Shadows: Pergolas, Pavilions, Tents, Cables, and Plants (E-book). Basel: Birkhäuser, 2011.

SALADO, G. C. Diferentes Alternativas de Materiais e Técnicas Construtivas. Trabalho Final de Graduação. São Paulo: Faculdade de Arquitetura e Urbanismo da Universidade Presbiteriana Mackenzie, 2003.

SALADO, G. C. Construindo com tubos de papeIão: um estudo da tecnologia desenvolvida por Shigeru Ban. Dissertação (mestrado). São Carlos: Universidade de São Paulo: Escola de Engenharia de São Carlos, 2006.

SALADO, G. C. Painel de vedação vertical de tubos de papelão: estudo, proposta e análise de desempenho. Tese (doutorado). São Carlos: Universidade de

\section{AUTORES}

ORCID: https://orcid.org/0000-0001-7292-0904

NATHALIA SCHIMIDT DIAS | Universidade Estadual de Campinas

- Faculdade de Tecnologia | Ciência dos Materiais | Limeira, São Paulo (SP) - Brasil | Correspondência para: Rua Paschoal Marmo, 1888, Jardim Piratininga, Limeira SP, 13484-332 | e-mail: nathalia.schimidt@hotmail.com

ORCID: https://orcid.org/0000-0002-0756-0284

GERUSA DE CÁSSIA SALADO, Dra. | Universidade Estadual de Campinas - Faculdade de Tecnologia | Tecnologia da Construção de Edifícios; Engenharia de Transportes Limeira, São Paulo (SP) - Brasil | Correspondência para: Rua Paschoal Marmo, 1888, Jardim Piratininga, Limeira SP, 13484-332 | e-mail: salado@unicamp.br

\section{COMO CITAR ESTE ARTIGO}

DIAS, Nathalia Schimidt; SALADO, Gerusa de Cássia. Utilização De Tubos De Papelão Para A Construção De Uma Estrutura De Pergolado. MIX Sustentável, [S.I.], v. 7, n. 4, p. 127-136, set. 2021. ISSN 24473073. Disponível em:<http://www.nexos.ufsc.br/index.php/ mixsustentavel>. Acesso em: dia mês. ano. doi:https:// doi.org/10.29183/2447-3073.MIX2021.v7.n4.127-136.

DATA DE ENVI0: 30/06/2021

DATA DE ACEITE: 02/07/2021 